\title{
Understanding the Assessment in Higher Education in South-east Asia: Four Perspectives
}

\author{
(Joan) Sau Kwan Chung \\ The Hong Kong Polytechnic University, Hong Kong SAR
}

\begin{abstract}
In our traditional Chinese culture, there is the widespread dominance of the exam-oriented curriculum with limited students' engagement in learning. This study is aimed at understanding the assessment issues and investigating the perspectives and experiences towards the assessment of the subject coursework and thesis at doctoral level in South-east Asia since there is scant study on this specific context. Relevant documents and the indepth individual interviews of a few learners and teachers were used to get complementary perceptions on this issue. This paper is analyzed based on several perspectives: the purposes for assessment, language assessment policy, assessment standards and frameworks, and factors affecting the assessment performance. Findings include the coursework assessment practice has aligned with $A F L$ - Assessment for learning. Assessment is embedded in the teaching and learning context. Individual abilities including the language proficiency and educational knowledge of learners, and the circumstances are factors related to the performance of the assessment in higher education.
\end{abstract}

\section{Introduction}

In our traditional Chinese culture, there is the widespread dominance of the exam-oriented curriculum with limited students' engagement in learning. Learners become spoon-fed by teachers and rote learning is the norm in most educational settings. Also, the summative assessment based on norm-referencing means that students' academic results merely conform to a pre-set distribution, without any indication of how much progress they have made. After all, this type of assessment is an oversimplification of teaching and learning [13]. Also, the giving of marks at the end of schooling is over-emphasized as the giving of advice and learning opportunities tend to be neglected [2].

Language assessment is to give valid and reliable interpretations of the assessment performed by particular learners in a context [8]. At doctoral level, other modes of assessment (e.g. assessment for learning and criterion-referenced assessment) have occupied a prominent role and are relatively novel mechanisms for both teachers and learners. Personal improvement is highlighted rather than competition among learners. Both pedagogy and assessment concern how learning is best achieved [2].

This study is a qualitative, exploratory research which helps to understand the assessment of the subject coursework and the thesis at doctoral level since there is scant study on this specific context. The in-depth interviews both from the lecturers and learners were used in order to get complementary perceptions on this issue. This paper is analyzed based on several perspectives: the purposes for assessment, language assessment policy, assessment standards and frameworks and factors affecting assessment performance as follows:

\section{Formatting your paper}

\subsection{Purposes for assessment}

The primary purpose is to indicate the learners who have certain ability for the intended outcomes. It is to inform whether learners are academically ready for pursuing further study so that a prospective learner has the ability to pursue the study successfully in the next academic setting. Another use of assessment is to give information about learners' progress. It is for guiding instruction and learning, a diagnostic assessment of learners' competence. Also, it is aimed at certifying learners have mastered certain standards of knowledge and skills for the intended purpose. In brief, it is to give information for making certain decisions [1].

\subsection{Purposes for assessment}

A good assessment is a viable mechanism for informing teachers what to teach and learners understand they have learnt. More essentially, learners can take an active role in class and be more responsible for their learning. It is certainly appropriate to emphasize 'Assessment for Learning' and fuse it into part of teaching-and-learning components. Such is a very good move from the norm-referenced, external examination to the educationally meaningful, student-centred, formative 
assessment [2]. The use of differentiated assessment tasks is beneficial for learners in terms of more learners' participation and learning outcomes. Indeed, 'Assessment for Learning' is theoretically sound and can enhance improvement in learners, who are informed to have the desired intended learning outcomes as a target. This language policy is associated with particular kinds of learning outcome - critical thinking, creativity, communication, independent learning or teamwork [6].

\subsection{Assessment standards and frameworks}

Assessment standards and framework have been increasingly used in education nowadays. Aligning different learning tasks and assessment contexts to the same proficiency framework would require some kind of modification and judgement. Inevitably the learning and assessment contexts differ, resulting in differentiated tasks. Yet it is still valid and useful to relate the specific contexts to the general framework. The wider framework can be a neutral point for reference in the specific context. Feasibility is necessary so as to implement 'standard-based' education. The use of a framework requires adaptation to particular situations, and it is not merely a simple interpretation [11].

There are some merits for using descriptive proficiency in assessment. It helps to describe and convey information about learners' performance at a particular level, thus providing appropriate feedback for learners. Besides, it has the function of providing guidance for raters regarding the quality of the performance. The can-do rating instrument is still promising for teachers' rating [8]. For example, the Common European Framework is a descriptive scheme informing learners' competence or achievement in a particular context. There are a set of common reference levels, where six categories such as A1, A2 and B1 are descriptors for the performance [12]. The framework is context-free but context-relevant, which can be applied in different contexts and be translated into relevant contexts [11].

\subsection{Factors affecting assessment performance}

Many factors affect the assessment performance, including learner characteristics, language background, age, profession and gender [10]. Learners' certain characteristics would lead to have better assessment. One is the personality factor, where extroverted learners are more talkative, relatively adventurous and responsive, would have a better communicative ability compared with those introverted learners. The role of motivation and attitude also play an essential role in assessment. To fulfil the professional ambition, learners would perceive the value of assessment; they are therefore more motivated, and adopt a more favourable learning attitude. The motivation to reach the practical goal is called instrumental motivation. The eagerness to pursue personal growth and cultural enrichment is the integrative motivation [9].

\section{Research questions}

Based on the four stances, the research questions are as follows:

- What are the purposes for the assessment in the coursework / the thesis and the language assessment policy at doctoral level?

- To what extent 'Assessment for Learning' has fused into part of the teaching and learning components?

- What factors affect the assessment at doctoral level?

\section{Methodology}

\subsection{Overall research method}

This study adopted an exploratory orientation in research design; relevant documents and the perspectives of 3 teachers and 5 learners towards the coursework and thesis were examined. Three teachers and five learners' views were the focus. The issue of sampling representativeness is acceptable in this small-scale study. The group selected includes different dimensions such as age range (30s to 60s), gender, nationality (British, Hong Kong Chinese and Mainland Chinese).

\subsection{In-depth individual interviews}

Interviewing is one of the major methods of data collection for the educational researchers. It allows us to have a better understanding of how people view the issue or get people's knowledge in particular contexts. Such information may not be obtained from other sources. Interview data is a window into the minds of informants or provider of the information of the contexts [3].

In this study, the in-depth individual interviews were carried out in a quiet place within forty-five minutes. Hopefully, the interviewees would feel relaxed and give their inner, genuine views. Efforts to build rapport are unnecessary as I have good relationship with the teachers and learners concerned. The interviews were informal and openended, and I tried to prevent my bias during the process. Semi-structured interviews were carried out in contexts [3]. The interviewees were professional adults capable of using their own English language to reply concisely. The open-ended questions were largely based on four stances, where the questions 
for the learners differed slightly from those of the teachers. The interviews varied in what questions were asked and in what order. In some cases, new questions were inserted for the follow-up [3]. The accurate and valuable perspectives of both learners and teachers were obtained, which may or may not be in line with the established theories.

At doctoral level, it is a taught programme where learners are required to take eight coursework modules before embarking the thesis proposal and final thesis. This study is concerned with the assessment of the subject course work and the thesis.

\section{Findings and discussion}

\subsection{Purposes for assessment}

The doctorate is an outcome-based curriculum, including three institutional learning outcomes and seven intended learning outcomes acting as a framework for the compulsory and elective subjects $[4,15,16]$. Learners are hoped to attain certain level of competence in the coursework [8]. In some coursework, the individual PowerPoint presentations are the assessment tools for learners' language ability--to express sophisticated academic ideas at doctoral level - proficiency goal. Also, both the spoken and written assessments measure a particular level of critical, analytical and creative thinking skills in the subject knowledge - cognitive goal. Besides, through doing the small-scale research projects, learners have to use certain research methods to get primary data and for evidence-based analysis in education-related area - transfer goal [4, $8,15,16]$.

Moreover, in the coursework, an important purpose is to cope with the vast differences among learners who have diverse cognitive styles, and stylistic profiles. The existence of these is incorporated into the assessment components. A good assessment tool is part of the learning experience and that learners working on projects engaging them, holding their interest and motivating them are novel [7]. This is in line with a teacher's view:

$\mathrm{T}$ : In this coursework, there are two options for learners to do, either a review paper or a miniresearch project. Also, learners can select their own favourable topics in the assignment for assessment. The variations in assessment place the importance of creative individuals in different domains. It is hoped learners can enjoy learning and later have an independent mode of learning in the related-study before their specialized thesis. Ample room is given to learners to explore the subject matter they like. This doctoral programme is not bound by rigidity, unlike the MA programme where there are more restrictions, fewer choices of subjects and a careful task control'.
For Thesis I, students need to write a research proposal in 10000 to 15000 words, guided by their supervisor and then give an oral presentation lasing for about 30 minutes and followed by a 30-minute Question and Answer (Q \& A) session, assessed by the Internal Assessment Panel. The purposes are to ensure the proposed research is of good quality and originality of the students [8], and to provide a chance for them to get feedbacks for the research. The assessment panel will assess whether the proposed research can be proceeded to Thesis II or major revisions are required $[15,16]$. The assessment is to give information for making the above decisions [1].

For Thesis II, students would be given an opportunity to conduct an independent research, guided by their supervisor. Specifically, they need to show the ability and a critical understanding of integrating linguistic theories to professional practice, knowledge from language-related discipline, international perspective and local context and gaining knowledge of different languages and/or cultures $[15,16]$. For the oral defense, a Thesis Assessment Panel (TAP) would be formed as the examiners who assess the research in terms of originality, the integration of theories and techniques, and whether the written work is publishable or not [8]. After the oral examination, the TAP would decide if the student should be awarded the doctorate. If not, minor or major amendments are required within a time limit. If the thesis is assessed as grade D, learners would be awarded the degree of master only $[15,16]$. Again, the assessment is to give information for making the above decisions [1].

Some students shared their experiences in Thesis I and II as below:

S: For Thesis I, I think it is not so difficult, and I can get $\mathrm{B}+$. Yet $\mathrm{I}$ find there is a big gap between Thesis I and II in terms of the written work. I need to spend lots of efforts on my writing.

S: I find the oral exam useful and practical. My ideas were stimulated from some more ideas from peers and teachers.

\subsection{Language assessment policy}

In each coursework, there are a variety of assessments tasks designed by the subject teachers for the learners, such as research projects, oral presentations, group discussion and term papers [15, 16]. Through these assessment and learning activities, learners are expected to arrive at the intended learning outcomes, which are not assessed by the formal written tests [6]. The coursework assessment practice has aligned with AFL Assessment For Learning, which is a fundamental 
component of the postgraduate assessment policy. There are related views on the AFL:

T: 'Assessment for learning is useful; it's PolyU's basic policy and the syllabus in this program. It is largely linked to the learning outcome.'

T: 'AFL may have desirable washback effect on teaching and learning... but I agree... the individual PowerPoint presentations are good assessment and practice giving learners the chance to express sophisticated academic ideas at doctoral level.'

S: 'I think thesis writing can help my written work and helps me to cultivate a critical mindset. The oral exam is necessary and practical as we learners can revise the thesis again and the Q-A session is challenging. I was told I need to get immersed with the thesis by my colleague and need to prepare for the unpredictable questions.'

S: Since group discussion occupied $20 \%$, I spent time reading the articles so as to prepare for group discussion. If not, I cannot participate in the learning process.

Both 'learning is for assessment' and 'assessment is for learning' are interrelated. Apart from the conventional written paper, assessment is embedded in the teaching and learning context. An appropriate context is provided for assessing the competence of learners. The assessment is also part of learners' engagement in a learning situation occurring on a reliable schedule [7]. Indeed, all the subject coursework are in the appropriate sequence of part-skills to the whole thesis later.

Additionally, the AFL is not only concerned with learning opportunities but associated with the content of feedback for learners' benefit. It touches on learners' motivations and self-perceptions; the feedback enhances attitudes and beliefs on the capacity to learn better [2]. AFL is associated with the content of feedback for learners' benefit, an aid to learners, identifying strengths to build on and shortcomings with suggestions of what should be improved [7]. All feedback, formal or informal, spoken or written can inform learners to address the weaknesses [5]:

S: 'One professor commented a lack of coherence in my written though I had few grammatical mistakes... and then I paid more attention to that and I now produce a more coherent paper. Also, my incorrect use of in-text references has been pointed out by two teachers and I think I need to improve that, which was neglected in my M. A.'

S: 'The constructive feedbacks in both Thesis I and II help me put forward the organization, ideas and English written work a great deal. For example, I need to give equal importance to the two regions in my thesis, rather than putting one as the secondary. Thus, the research project is much better. Also, I need to eliminate something less important in discussion of findings section, with a focus on research questions. After making all these amendments, my thesis is novel'.

As a result of the feedbacks, learners can make continuous progress in the eight coursework and their thesis [7]. It would be a difference if learners believe effort is more crucial than ability and mistakes are inevitable, thus leading to greater academic improvement [2]. Teachers would review the assessment data regularly [6] in order to give a fair assessment to learners. Teachers and students remarked two teachers' assessment of the written work is more accurate. For example:

T: 'In this course, we teachers would have double markings for students' papers as we might be judgmental- too strict or lenient in our markings. Also, we teachers do have a regular meeting for discussion of learners' grades.'

S: 'I think one teacher's comment can be biased, but two or more assessors can give a more accurate assessment and more feedbacks on my coursework and thesis. My weakness is shown and then I made more efforts in response to the feedbacks. Feedbacks are a guide to improve my writing.'

\subsection{Assessment standards and framework}

At the doctoral level, all the coursework is graded on a criterion-reference basis. Totally, there are nine descriptors both short and full for the subject grade $(\mathrm{A}+, \mathrm{A}, \mathrm{B}+, \mathrm{B}, \mathrm{C}+, \mathrm{C}, \mathrm{D}+, \mathrm{D}$ and $\mathrm{F})$. The descriptor is not in detailed but can help learners to understand the performance $[15,16]$.

\section{Grading}

Assessment grades shall be awarded on a criterion-reference basis. A student's overall performance in a subject outlined in Table 1.

Some students, for example, commented the grading system positively, which can provide information about their performance [8]:

$\mathrm{S}$ : 'I get mostly $\mathrm{B}$ grade or $\mathrm{B}+$ and I can easily understand my performance. The descriptor grade $\mathrm{B}$ distinguishes from grade $\mathrm{B}+$ only a little bit. Accordingly, the short descriptor for the former is 'good' and the latter is 'very good'. In the full descriptor, the former is learners' work is good and exceeds the intended subject learning outcomes in some regards while the latter is slightly differentvery good and in most regards'.

S: 'In some courses, the assessment criteria are given at the beginning of the course, which is very useful for me. While doing the assignment, I try to meet that criteria'. Thus I can get grade A in oral presentation in a course and grade B in a miniresearch'. 
Table 1. A student's overall performance

\begin{tabular}{|c|c|c|}
\hline Subject grade & Short Descriptor & Full Descriptor \\
\hline $\mathrm{A}+$ & Exceptionally outstanding & $\begin{array}{l}\text { The student's work is exceptionally } \\
\text { outstanding. It exceeds the } \\
\text { intended subject learning } \\
\text { outcomes in all regards. }\end{array}$ \\
\hline A & Outstanding & $\begin{array}{l}\text { The student's work is outstanding. } \\
\text { It exceeds the intended subject } \\
\text { learning outcomes in nearly all } \\
\text { regards. }\end{array}$ \\
\hline $\mathrm{B}+$ & Very Good & $\begin{array}{l}\text { The student's work is very good. } \\
\text { It exceeds the intended subject } \\
\text { learning outcomes in most regards. }\end{array}$ \\
\hline $\mathrm{B}$ & Good & $\begin{array}{l}\text { The student's work is good. It } \\
\text { exceeds the intended subject } \\
\text { learning outcomes in some regards. }\end{array}$ \\
\hline $\mathrm{C}+$ & $\begin{array}{l}\text { Wholly Satisfactory } \\
\text { Satisfactory }\end{array}$ & $\begin{array}{l}\text { The student's work is wholly } \\
\text { satisfactory. It fully meets the } \\
\text { intended subject learning } \\
\text { outcomes. }\end{array}$ \\
\hline $\mathrm{C}$ & 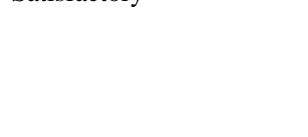 & $\begin{array}{l}\text { The student's work is } \\
\text { satisfactory. It largely meets the } \\
\text { intended subject learning } \\
\text { outcomes. }\end{array}$ \\
\hline D+ & Barely satisfactory & $\begin{array}{l}\text { The student's work is barely } \\
\text { satisfactory. It marginally meets the } \\
\text { intended subject learning } \\
\text { outcomes. }\end{array}$ \\
\hline & Barely adequate & \\
\hline $\mathrm{D}$ & Inadequate & $\begin{array}{l}\text { The student's work is } \\
\text { barely adequate. It meets } \\
\text { the intended subject learning } \\
\text { outcomes only in some regards }\end{array}$ \\
\hline $\mathrm{F}$ & & $\begin{array}{l}\text { The student's work is inadequate. It fails to meet } \\
\text { many of the intended subject learning outcomes }\end{array}$ \\
\hline
\end{tabular}

S: 'The full descriptors are useful and can indicate my performance to a certain extent, whether or not meeting the intended learning outcomes in all regards, nearly all regards or most regards'. I understand and know my ability is good, neither outstanding nor satisfactory'.

As we shall see, the brief descriptors are valuable for helping learners to know their performance to a certain extent [8]. The construction and analysis of the scale is put upon the distinction between or among levels. The learners can have a general picture of their academic performance at doctoral level. Besides, proficiency framework can act as learning ladders for learners, giving a valid description and interpretation of the competence achieved [8]. It is the crucial goal for learners to achieve as well. At the doctoral level, getting A+ is explained as a learner's work should exceed in all aspects $[15,16]$.

For thesis I and II, the assessment criteria are outlined in Table 2.

For thesis II, there would be the assessment of students' ability to address the examiners' comments $[15,16]$.

\subsection{Factors affect assessment}

At doctoral level, most students' motivation of learning is generally good. Their personal preferences or goal are the factors for the assessment performance. Learners are professionals such as teachers or research assistants at university. 
Table 2. Assessment of the Overall Quality of the Thesis

\begin{tabular}{|l|l|l|l|l|l|}
\hline Criterion & Excellent & $\begin{array}{l}\text { Very } \\
\text { good }\end{array}$ & Good & Satisfactory & $\begin{array}{l}< \\
\text { satisfactory }\end{array}$ \\
\hline $\begin{array}{l}\text { Originality } \\
\text { of } \\
\text { the work }\end{array}$ & & & & & \\
\hline $\begin{array}{l}\text { Significance } \\
\text { of the work }\end{array}$ & & & & & \\
\hline $\begin{array}{l}\text { Quality of } \\
\text { presentation }\end{array}$ & & & & & \\
\hline $\begin{array}{l}\text { Quality } \\
\text { and/or } \\
\text { accuracy of } \\
\text { results }\end{array}$ & & & & & \\
\hline $\begin{array}{l}\text { Appropriate } \\
\text { ness of the } \\
\text { conclusions }\end{array}$ & & & & & \\
\hline $\begin{array}{l}\text { Adequacy of } \\
\text { references }\end{array}$ & & & & & \\
\hline $\begin{array}{l}\text { Overall } \\
\text { Rating of the } \\
\text { Thesis }\end{array}$ & & & & & \\
\hline
\end{tabular}

The efforts they have put on the subject coursework largely depend on their goals for work, publication, pilot studies for their thesis or personal interests:

S1: 'If I want to get my paper published, I would spend more time on the paper. If not, a pass is my target then. Also, my personal preferences of particular topics, or teachers' teaching strategy also would affect me to get good marks in some coursework'.

S2: 'Because of limited time, I can only spend more time on the subject that is highly potential to be my thesis. The other coursework would be secondary only and I put less effort on them. Also, I would like to survive at tertiary level. I need to have a thorough understanding of my knowledge, so I study harder to get better grade'.

Individual factors also include a lack of knowledge of and abilities in conducting research, identifying a doable and worthwhile topic, asking useful and relevant research questions, and knowing suitable research methods. Others include the academic/ research writing skills are not proficient, nor knowing the structure and language of the appropriate genre. These are remarked by a teacher and two learners.

The coursework subjects and the thesis are in English medium, where all the spoken and written assessments are certainly in English language. In this way, learners' differences in their English Language proficiency and the educational background knowledge of particular topics would affect the assessment grade [7], for example:

S: 'English Language proficiency - one need to be good in English in order to communicate their thoughts well, in speaking and writing, to the teachers, that affect my grade most! Besides, the background (prior) knowledge of my profession knowledge helps one to make connections with new information and ease understanding of new concepts, which presumably can help one to put forward a stronger argument in my term paper'.

S: 'I will choose some topics related to my teaching context or educational background so I can have lots of ideas in my English written work. Also, my reading and writing skills are good so I can have good grades in written work as a whole. However, I am a bit anxious about my spoken assessment in front of the audience and also I am an introvert learner, therefore oral presentation is affected'.

S: 'I think having a linguistic educational background is vital. My previous knowledge at BA and MA can be revised and consolidated.

S: "Two classmates quitted their study owing to a lack of linguistic education. They found the theories are difficult to understand. I love reading English journal articles and got some background knowledge in linguistics knowledge.

Time management and external circumstances can be vital factors influencing the performance as remarked by two teachers and three learners, for example:

$\mathrm{T}$ : 'Poor time management, especially those working full time, would have made them get a 
satisfactory result only'. Some students have health or family problems, thus affecting their performance'.

S: 'As a whole, I can produce assignment of good quality. I work part time, so I can spend more time researching good articles and on assignment than those working full time.

S: I find some classmates occupied with their busy full-time work. They are too busy or tired to produce good quality of work. Their performance may be satisfactory only or get a pass. Some told me they have little sleep every day and some shared they were sometimes sick on weekends and no time for their study. Yet I can have some more time spent on my study as I work part time only.

As indicated in the above, individual abilities and the background knowledge are vital factors, which are quite in line with the multiple intelligence perspective stressing vast differences - intellectual merits and demerits, language ability, and varied cognitive styles. Such different components would inevitably contribute to the results of the assessment [7]. Additionally, external circumstances and time management would affect the assessment performance.

\section{Conclusion and recommendation}

As previously discussed, assessment is not confined to the summative assessment. There are different modes of assessment: AFL and the criterion-referenced assessment largely align with the learning theories emphasizing learning process. It is hoped that all learners can learn, and assessments can facilitate learning. The diversified modes of learning place more emphasis on expression of ideas, knowledge building, creativities and thus suit learners' differences [5]. Inevitably, they have some shortcomings; there may be varied judgements by teachers [14]. Nevertheless, the assessments are more capable of meeting today's needs - learners can be imparted with facts of knowledge, cultivated with skills and understanding. The implementation of AFL which is theoretically and practically beneficial for learning would help getting the desired learning outcomes and lead to continuous improvements. On account of the assessments, self-regulating, independent, critical, creative learners can be produced at doctoral level [6]. Assessment is a complicated issue, important factors such as learner preferences and educational background would affect the assessment [9]. In the coming future, self or peer assessment can be incorporated in order to enhance self-awareness and self-reflection, leading to a strategic approach for study [2].

\section{References}

[1] Bachman, L.F. \& Purpura, J.E., (2008). Language Assessments: Gate-Keepers or Door Openers? In Spolsky, B. and Hult, F.M (eds.), Handbook of Educational Linguistics. Oxford: Blackwell Publishers.

[2] Black, P., (2006). "Assessment, Learning Theories and Testing System" In Murphy, P. (eds.): Learners, Learning and Assessment. London: UK Open University.

[3] Chung, S-K., (2017). The Identities of Overseas Teachers at University in HKSAR. The international Journal of Diverse Identities, 17 (2), 1-10.

[4] Chung, S-K., (2019). A Critique on Curricular Designs: Two Case studies in Hong Kong. The International Journal of Technology and Inclusive Education (IJTIE), 8 (1), ISSN 2047-0533 (Online).

[5] Curriculum Development Council, (2001). Learning to Learn: life-long learning and whole-person development, Hong Kong, Printing Department.

[6] Davison, C., (2013). Innovation in Assessment: Common Misconceptions and Problems. In K. Hyland and L.L.C. Wong (eds.), Innovation and Change in English Language Education. London and New York: Routledge.

[7] Gardner, H., (2006). "Assessment in Context". In Murphy, P. (eds.): Learners, Learning and Assessment. London: UK Open University.

[8] Jones, N. \& Saville, N., (2008). Scales and Frameworks In Spolsky, B. and Hult, F.M (eds.) Handbook of Educational linguistics. Oxford: Blackwell Publishers

[9] Lightbown, P. \& Spada, N., (2001). "Factors Affecting Second Language Learning" In N. Christopher, N. Candlin and N, Mercer (eds.): English Language Teaching in its Social Context. London: UK Open University.

[10] Lumley, T. \& O'Sullivan, B., (2005). The Impact of Test Taker Characteristics on Speaking Test Task Performance. Language Testing, 22, 4: 415-437.

[11] North, B., (2008). Levels and Goals: Central Frameworks and Local Strategies. In Spolsky, B. and Hult, F. M. (Eds.) Handbook of Educational Linguistics. Oxford: Blackwell Publishers

[12] North, B. \& Schneider, G., (1998). Scaling descriptors for Language Proficiency Scales, Language Testing, 15 (2), 217-262.

[13] Richards, J.C., (2013). Curriculum Approaches in Language Teaching: Forward, Central and Backward Design RELC Journal, 44(1), 5-33.

[14] Stenhouse, L., (1975). "A Critique of the Objective Model and a Process Model" In Scott, D (Eds.): Curriculum Studies. London: Routledge. 
International Journal of Technology and Inclusive Education (IJTIE), Volume 8, Issue 1, June 2019

[15] Wu, D. \& Mathiessen, (2014). Doctor of Applied Language Science Handbook. Hong Kong: Hong Kong Polytechnic University.

[16] Wu, D. \& Mathiessen, (2018). Doctor of Applied Language Science Handbook. Hong Kong: Hong Kong Polytechnic University. 